\title{
Coracoid Process Fracture: A Report of Two Cases and Brief Review of Literature*
}

\author{
Paragjyoti Gogoi ${ }^{1}$, Anshuman Dutta ${ }^{1}$, Aditi Das ${ }^{2}$, Prasanta Sonowal ${ }^{3}$ \\ ${ }^{1}$ Department of Orthopaedics \&Trauma, Silchar Medical College, Silchar, India; ${ }^{2}$ Department of Radio-Diagnosis Silchar Medical \\ College, Silchar, India; ${ }^{3}$ Department of Anaesthesiology, Silchar Medical College, Silchar, India. \\ Email: pggogoiparag@gmail.com
}

Received April 26 ${ }^{\text {th }}, 2013$; revised May 25 ${ }^{\text {th }}, 2013$; accepted June $3^{\text {rd }}, 2013$

Copyright (C) 2013 Paragjyoti Gogoi et al. This is an open access article distributed under the Creative Commons Attribution License, which permits unrestricted use, distribution, and reproduction in any medium, provided the original work is properly cited.

\begin{abstract}
Coracoid process of Scapula fracture is not a common entity. Because of its deep anatomic location, they hardly sustain any direct traumatic force. Most of the time, they get fractured by indirect force by the muscles and ligaments attached to them. They are usually associated with fracture of the acromion process of Scapula, acromio-clavicular dislocation and proximal humerus fracture or dislocation of the shoulder joint. They may be missed because more attention is drawn by the obvious injuries. We report two cases of coracoid process fracture, one is associated with fracture dislocation of the shoulder and the other with acromion process fracture.
\end{abstract}

Keywords: Coracoid Process; Scapula; Fracture; Coraco-Acromial Arch

\section{Introduction}

Coracoid process of scapula is rarely got fractured. Only a few cases are reported in the literature. They indeed comprise only $2 \%$ to $13 \%$ of the scapular fractures and the Scapular fractures amount approximately $1 \%$ of all fractures [1-3]. They are deep structures and the site for attachment of three muscles and two major ligaments. They take an important part in forming the coraco-humeral arch above the rotator cuff and also stabilize the clavicle by the coraco-clavicular ligament. Fracture of the coracoid disrupts the arch as well as compromise the shoulder function; hence requires surgical restoration of the anatomy. Our one case is associated with fracture dislocation of the proximal humerus and the other with fracture of the acromion process.

\section{Case 1}

A 25 year old boy sustained injury to right shoulder following fall while playing. He felt intense pain about the shoulder and the movement was extremely painful. On examination he had tenderness over acromion process and anterior aspect of the shoulder. His vital parameters were within normal limits. Plain X-ray of the shoulder revealed fracture of the coracoid process and an undisplaced fracture of the acromion process (Figure 1). CT

\footnotetext{
${ }^{*}$ The authors declare that they have no conflict of interests.
}

scan of the area confirmed the fracture of the coracoid process which was displaced and angulated (Figure 2).

He was taken for surgery after relevant pre-operative investigations. The coracoid process is approached by an incision incorporating the superior part of standard deltopectoral approach. The coraco-humeral, coraco-clavicular and coraco-acromial ligaments were found intact. All the muscles attached to the coracoid i.e. pectoralis minor, coraco-brachialis and short head of biceps was normal. The fracture was located at the base of the coracoid which was cleared of haematoma, reduced anatomically and fixed with a $4 \mathrm{~mm}$ cancellous screw under image intensifier (Figure 3). The wound was closed in layers and the shoulder immobilized. Range of motion exercises started at 2 weeks and strengthening exercises began at 6 weeks.

\section{Case 2}

This man of 35 years injured his shoulder following a road traffic accident. He presented to the emergency department with swelling and inability to move the shoulder along with extreme pain. X-ray showed fracture dislocation of the right shoulder (Figure 4). He was immediately taken to the emergency OT and the joint was reduced under anaesthesia. Post-reduction X-ray revealed greater tuberosity fracture with comminution (Figure 5). The coracoid process fracture was missed. 


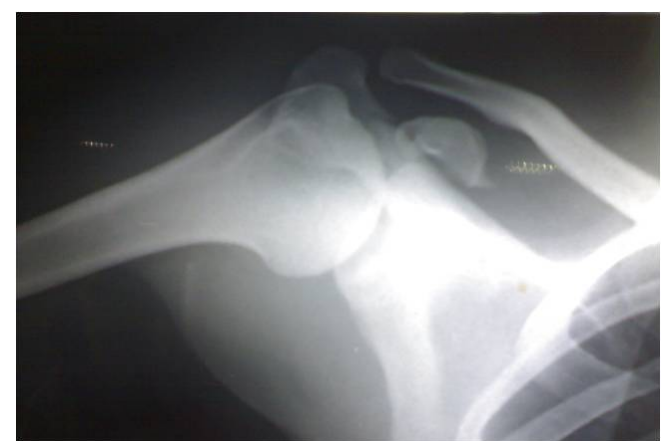

Figure 1. Case 1, X-ray showing fractured coracoid process and undisplaced fracture of acromion process.

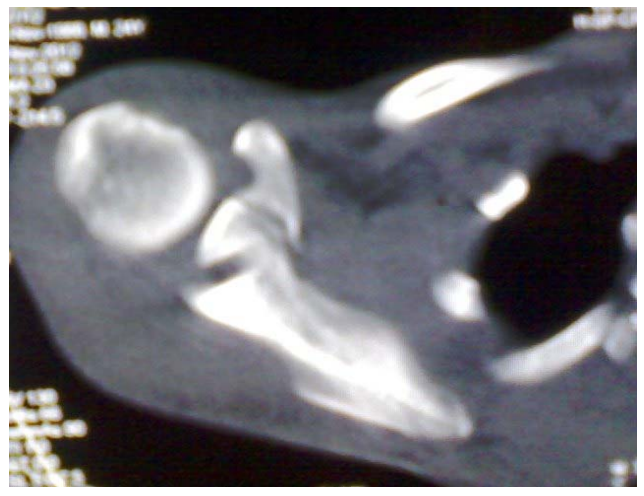

Figure 2. Case 1, CT scan appearance of coracoid fracture.

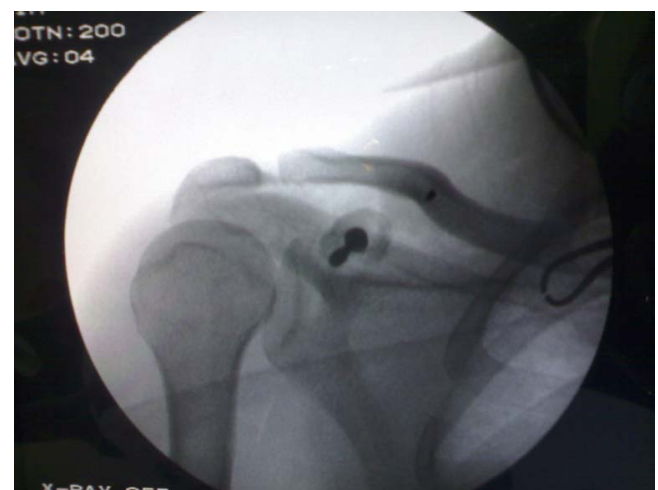

Figure 3. Case1, post-operative image in C-arm.

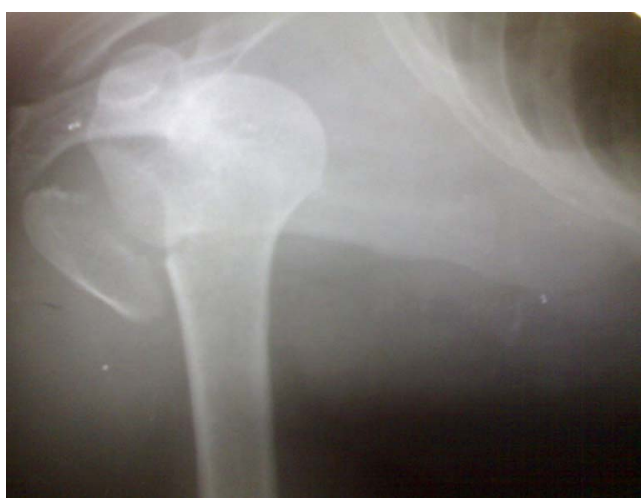

Figure 4. Case 2, fracture dislocation right shoulder.

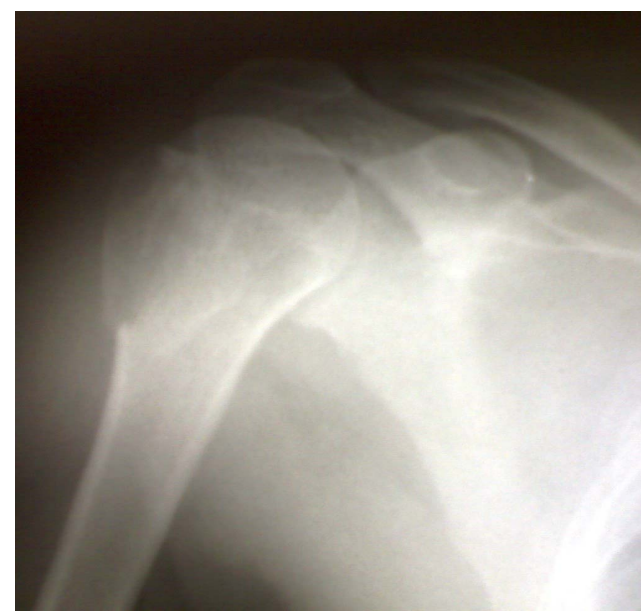

Figure 5. Case 2, after closed reduction.

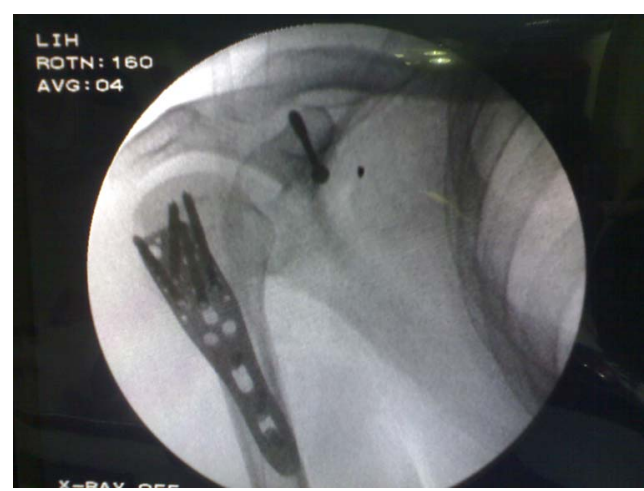

Figure 6. Case 2, post-operative C-arm image.

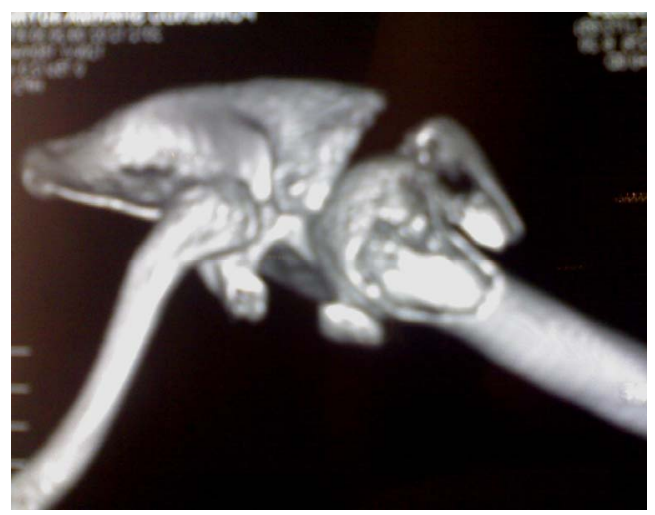

Figure 7. Case 2, 3D reconstructed CT image showing a vulsed tip of coracoid process.

The proximal humerus was exposed using the standard delto-pectoral approach. The fractured tuberosity was exposed, cleared of haematoma and clots and reduced. It was then fixed with a proximal humerus locking plate. Per-operatively the tip of the coracoid process was found avulsed with attached coraco-acromial ligament and the muscles. It was reduced after clearing the fracture bed and fixed with a $4 \mathrm{~mm}$ cancellous screw (Figure 6). 
Mobilization was delayed till the end of 3rd week and strengthening exercises started after 6 weeks.

Retrospective study of the CT image confirmed the avulsed fragment of the coracoid process (Figure 7).

\section{Discussion}

Although coracoid process has rarely got fractured it can be fractured by many ways. Few mechanisms are proposed for these fractures. First is direct trauma to the area [4]; second the continuum of forces that causes acromioclavicular disruption where during the dislocation the clavicle pulls the coracoid by the coraco-clavicular ligament causing avulsion [5]; and third by sudden resistance during forceful pull of the muscles attached to the coracoid like in flexion of the arm and elbow [6].

In shoulder dislocation, the dislocated head may directly hit the coracoid or it may forcefully push the coraco-acromial ligament which may avulse it. Some unexplained mechanism is also reported like in throwing a cricket ball [7].

They are associated with fracture of the acromion, proximal humerus, scapular spine, acomio-clavicular disruption and dislocation of the shoulder joint $[2,3,5,8]$. Isolated coracoid process fracture is very rare $[9,10]$. They may present rarely in a child which is usually avulsion type [11]. Coracoid fractures may be missed in routine radiographs. They are best seen in AP radiographs of shoulder with 45 to 60 degrees cephalad tilting and in Strykers Axillary lateral view [12]. Careful detailed history of the injury and proper radiographs have paramount importance in diagnosis.

Operative fixation of coracoid fracture is sparsely reported in the literature. Ogawa et al first reported one scientific series where he tried to classify the fractures according to required treatment [3]. They divided the fractures into two groups as Type I, those posterior to the attachment of coraco-clavicular ligaments and Type II those anterior to the ligament. Basically the first group is unstable fractures which eventually require operative fixation. The second group is mostly stable fractures and can be managed conservatively. Our first case belong to Ogawa type I and the second to Ogawa type II.

Eyers and collegues classified the coracoids fractures into five types according to its anatomical location as (I) avulsion of the tip of the coracoid; (II, III) fracture of the body of the coracoid; (IV) fracture at the base of the coracoid; and (V) fracture at the base with glenoid involvement. They also advocated fixation in displaced fractures [2].

Coracoid can be fixed with normal cancellous screw or cannulated cancelous screw over a guide wire. Ogawa et al used malleolar screw with washer in most of the cases in their series [3].

\section{Conclusion}

Fracture of the coracoid process of scapula is a rare one. It is usually presented along with other injuries around the shoulder girdle. If not suspected and investigated properly, they may be missed. Surgical intervention is required in displaced fractures to restore the normal function.

\section{Consent}

Informed consent was taken for this work.

\section{REFERENCES}

[1] J. R. Ada and M. E. Miller, "Scapular Fractures: Analysis of 113 Cases," Clinical Orthopaedics and Related Research, Vol. 269, 1991, pp. 174-180.

[2] K. S. Eyres, A. Brooks and D. Stanley, "Fractures of the Coracoid Process,” The Journal of Bone \& Joint Surgery, Vol. 77, No. 3, 1995, pp. 425-428.

[3] K. Ogawa, A. Yoshida, M. Takahashi, et al., "Fractures of the Coracoid Process," The Journal of Bone \& Joint Surgery, Vol. 79, No. 1, 1997, pp. 17-19. doi:10.1302/0301-620X.79B1.6912

[4] D. W. Boyer Jr., "Trapshooter’s Shoulder: Stress Fracture of the Coracoid Process. Case Report," The Journal of Bone \& Joint Surgery, Vol. 57, No. 6, 1975, p. 862.

[5] K. M. Wilson and J. C. Colwill, "Combined Acromioclavicular Dislocation with Coracoclavicular Ligament Disruption and Coracoid Process Fracture," American Journal of Sports Medicine, Vol. 17, No. 5, 1989, pp. 697-698. doi:10.1177/036354658901700521

[6] D. J. Hak and E. E. Johnson. "Avulsion Fracture of the Coracoid Associated with Acromioclavicular Dislocation," Journal of Orthopaedic Trauma, Vol. 7, No. 4, 1993, pp. 381-383. doi:10.1097/00005131-199308000-00016

[7] S. Asbury and T. D. Tennent, "Avulsion Fracture of the Coracoid Process: A Case Report,” Injury, Vol. 36, No. 4, 2005, pp. 567-568. doi:10.1016/j.injury.2004.11.002

[8] T. Martin-Herrero, C. Rodriquez-Merchan and L. Munuera-Martinez, "Fractures of the Coracoid Process: Presentation of Seven Cases and Review of the Literature," Journal of Trauma, Vol. 30, No. 12, 1990, pp. 1597-1599. doi:10.1097/00005373-199012000-00031

[9] R. C. Rounds, "Isolated Fracture of the Coracoid Process," The Journal of Bone \& Joint Surgery, Vol. 31, 1949, p. 662.

[10] P. P. Mariani, "Isolated Fracture of the Coracoids Process in an Athlete," The American Journal of Sports Medicine, Vol. 8, No. 2, 1980, pp. 129-130. doi:10.1177/036354658000800214

[11] P. Jettoo, et al., "Base of Coracoid Process Fracture with Acromioclavicular Dislocation in a Child," Journal of Orthopaedic Surgery and Research, Vol. 5, No. 1, 2010, p. 77. doi:10.1186/1749-799X-5-77

[12] M. DiPaola and P. Marchetto, "Coracoid Process Fracture With Acromioclavicular Joint Separation in an American Football Player: A Case Report and Literature Review," The American Journal of Orthopedics, Vol. 38, No. 1, 2009, pp. 37-40. 